\title{
SIMILITUDES Y DIFERENCIAS ENTRE LA EVIDENCIA DE AUDITORIA Y LA PRUEBA EN EL PROCEDIMIENTO JUDICIAL O ADMINISTRATIVO
}

\author{
JENNIFER ISABEL ARROYO CHACÓN \\ Contraloría General de la República, Costa Rica \\ prof.jenniferarroyo@yahoo.com
}

\section{RESUMEN}

El objetivo del presente documento es exponer las similitudes y diferencias entre la evidencia de auditoría y la prueba en un proceso administrativo o jurisdiccional, conceptos que si bien están íntimamente vinculados no pueden ser considerados como sinónimos. Para ello, el documento expone las características más importantes de la evidencia de auditoría junto con las normas técnicas que la regula; posteriormente, desglosa el concepto de prueba, los diferentes tipos de prueba que existen así como la normativa que le aplica en el ordenamiento jurídico costarricense; para finalmente, explicar las similitudes y diferencias de ambos conceptos. Concluye reiterando que si bien ambas figuras están íntimamente vinculadas y nacen producto del trabajo del auditor, ellas poseen naturaleza distinta y por lo tanto, el auditor debe estar consiente de dichas diferencias al momento de realizar su trabajo.

PALABRAS CLAVES: PRUEBA, EVIDENCIA DE AUDITORÍA, ESTUDIO DE AUDITORÍA.

\section{ABSTRACT}

The aim of this report is to contrast audit and legal evidence in an administrative or judicial process. Both concepts are similar and are related to each other, but they cannot possibly be used as synonyms. This article describes the most significant characteristics of audit evidence together with the technical criteria that regulate it; subsequently it describes the concept of legal evidence, its different types and the rules that are applied to it in the Costa Rican legal system; finally, it explains the similarities and differences between both concepts. This article concludes by reiterating that, although both forms are closely linked and are born of the auditor's work, they have different natures and, therefore, auditors should be aware of these differences when doing their work.

KEYWORDS: EVENTS, AUDIT EVIDENCE, AUDIT STUDY.

\section{INTRODUCCIÓN}

La auditoría es una de las ciencias del conocimiento humano con más desarrollo durante los últimos años. Las demandas son cada vez mayores y diversas, y la auditoría ha tenido que evolucionar para satisfacerlas, lo cual tiene como consecuencia una mayor exigencia para el auditor.

Dentro de estos cambios se encuentra el hecho que un producto de auditoría puede ser discutido posteriormente en un proceso de carácter jurídico, sea una investigación preliminar que se traslada al jerarca para que se instaure el procedimiento administrativo correspondiente, sea una denuncia penal que se envía al Ministerio Público advirtiendo sobre la posible comisión de un delito; o bien, un dictamen de estados financieros o un informe de auditoría que se haya impugnado en sede jurisdiccional.

Esta vinculación del producto de la auditoría con el ámbito jurídico conlleva a precisar dos nociones, que si bien están relacionadas no pueden ser consideradas como sinónimos, que son: evidencia de auditoría y prueba en el procedimiento administrativo o jurisdiccional. El objetivo del pre- 
sente documento es detallar las características principales de ambas figuras para posteriormente, demostrar sus diferencias, por lo tanto, se le invita a continuar leyendo el presente texto que pretende guiar al auditor en el desarrollo de sus funciones.

\section{Generalidades de la auditoría}

\section{Concepto de auditoría}

El término auditoría es un concepto que ha tenido una cambio significativo en los últimos años; inicialmente la auditoría se concebía únicamente como el proceso mediante el cual se verificaba que los estados financieros hubieran sido elaborados de manera correcta, es decir con un enfoque de auditoría financiero contable; no obstante, hoy este concepto es más amplio, e incluye diferentes tipos, tales como: auditoría operativa, auditoría de legalidad, auditoría de tecnologías de la información y la comunicación, auditoría de investigación, auditoría ambiental, y muchos más.

El presente documento no pretende realizar un análisis exhaustivo del concepto de auditoría, no obstante, para poder comprender la importancia de la evidencia de auditoría y su diferencia con la prueba en un proceso jurisdiccional o administrativo, señalaremos que auditoría es el proceso de verificación (realizado por un tercero, en este caso el auditor) de que las actuaciones de la institución se ajusten a los estándares y normas correspondientes, de tal manera, que las desviaciones entre la realidad y el deber ser se considera como hallazgos de auditoría.

\section{Productos del trabajo del auditor}

El campo de trabajo del auditor se ha incrementado de manera significativa en los últimos años, superando la tradicional auditoría de estados financieros para incursionar en otras áreas en las cuales ha tenido un gran éxito, tales como: auditorías de tecnologías de la información, audito- rías de cumplimiento, auditoría de desempeño, auditoría ambiental, investigación de actos de corrupción, atención de denuncias, asesoría y consulta, control interno y demás similares.

Lo anterior tiene como consecuencia una diversificación de los productos de auditoría, dado que ya no sólo se emite la opinión de estados financieros -producto tradicional de la auditoría financiera-, sino también, el auditor puede elaborar informes de auditoría de los tópicos analizados, sean los sistemas de información, control interno, emitir advertencias, prestar asesorías, e incluso productos con altas consecuencias legales tales como: una investigación preliminar que trasladará a la administración para que se instaure un procedimiento administrativo o una denuncia penal que se traslada al Ministerio Público con el aviso de la presunta comisión de un delito penal.

Precisamente en este segundo supuesto es donde cobra relevancia tener clara la diferencia entre evidencia de auditoría que es utilizada para respaldar informes de auditoría y opiniones de estados financieros, y la prueba en sede administrativa o jurisdiccional, que es la que se incluye en una investigación preliminar o denuncia penal.

Lo anterior reviste especial relevancia por la "fe pública" que la Ley Orgánica del Colegio de Contadores Públicos n. ${ }^{\circ} 1038$ de 19 de agosto de 1947, le otorga al Contador Público Autorizado, y por ende, se considera como válido y plena prueba todo documento elaborado por dicho profesional en la rama de la contaduría.

A continuación, se precisarán un poco más estos conceptos:

\section{a) Opinión sobre Estados Financieros}

La opinión de Estados Financieros o Dictamen sobre los Estados Financieros es el producto tradicional de la auditoría financiera, en donde el auditor emite una opinión producto de la revisión realizada de los estados financieros. Asimismo, esa opinión puede ser 
de diferentes tipos, tales como: Opinión No modificada -según NIA 700- así como, modificada con párrafo de énfasis o con párrafo de otros asuntos -según NIA 701-. También, está la opinión modificada -según NIA 705con salvedad, negativa o abstención -según NIA 706-. El Dictamen sobre Estados Financieros es el documento en donde el auditor emite su opinión sobre los estados financieros que revisó en su estudio, pudiendo ser de cualquiera de los tipos citados.

b) Informe de auditoría

El informe de auditoría es el producto de los diversos tipos de estudios de esta índole; que incluirá los matices propios de cada tipo de revisión realizada. Para (Armas García, 2008) representa el resultado del examen realizado; en esta fase el auditor expresa en forma escrita, el papel y los resultados derivados de aplicar los procedimientos analíticos y explica los hallazgos encontrados en términos de condición, criterio, causa y efecto, terminando con las conclusiones del estudio y las recomendaciones al ente auditado.

El informe de auditoría es el documento en el cual el auditor plasma las conclusiones y hallazgos, siguiendo los criterios de condición, criterio, causa y efecto, encontrados como producto de su estudio de auditoría, y que se encuentran respaldados en evidencia de auditoría.

c) Investigación Preliminar

La investigación preliminar es el producto del proceso de indagación realizado por el auditor, quien luego de la revisión de hechos y recopilación de prueba determina existen indicios de una supuesta falta; por lo que plantea una hipótesis sobre la presunta comisión de un acción antijurídica, con el objetivo de remitirlo como un insumo al ente competente de determinar la veraci- dad de los hechos y verificar la existencia de eventuales responsabilidades administrativas, civiles y/o penales, derivadas del ejercicio de la función pública.

La investigación preliminar se basa en evidencia de auditoría que se tornará prueba en el procedimeinto administrativo,de allí la importancia de que el auditor tenga clara la diferencia entre ambas figuras, y sepa que el proceso de recopilación de evidencia que se convertirá en prueba es mucho más riguroso que si estuviera elaborando un informe de auditoría.

En este punto se recuerda la importancia de la norma internacional de auditoría NIA 240: Responsabilidad del auditor en relacion al fraude en una auditoría de Estados Financieros, así mismo, dicha responsabilidad se mantiene si el fraude es detectado en cualquier otro tipo de auditoria distinta de la auditoría de Estados Financieros tradicional.

\section{d) Denuncia Penal}

La denuncia penal es el acto de poner en conocimiento de la autoridad judicial competente la posible comisión de un delito. Cuando producto de una auditoría o investigación, el auditor determina que está frente a un delito penal elaborará un informe donde indicará los hechos encontrados, los presuntos responsables, la eventual normativa violentadas, y los documentos que respaldan dicha denuncia, o bien, el lugar donde podrán ser ubicados.

Dado el carácter tan riguroso del proceso penal, cuando el auditor detecta que esta frente a un delito de tipo penal, sea por fraude fiscal, estafa, alteración de estados financieros, mal uso de fondos públicos u cualesquiera otro debe ser altamente riguroso en la selección y recopilación de evidencia de auditoría dado que ésta será la prueba en el proceso jurisdiccional correspondiente. 


\section{Evidencia de auditoria}

\section{Concepto de evidencia de auditoría}

Los resultados del estudio de auditoría, denominados hallazgos de auditoría deben estar respaldados en evidencia de auditoría, independientemente si hablamos de auditoría financiera, operativa, tecnologías de información o cualquier otra; en este punto surge la consulta ¿Qué es evidencia de auditoría?

La evidencia de auditoría es toda información obtenida por el auditor durante un estudio de auditoría que cumplen la función de sustentar los hallazgos de auditoría y las conclusiones del auditor expresadas en un informe.

Desde la perspectiva técnica, la Norma Internacional de Auditoría NIA 500: Evidencia de auditoría define esta figura como: "Información que usa el auditor para obtener las conclusiones en las que se basa su opinión como auditor. La evidencia de auditoría incluye la información contenida en los registros contables que subyace a y/o es soporte de los estados financieros y otra información" (International Federation of Accountants, 2009, p. 458).

La anterior definición se enfoca en la evidencia que sirve de respaldo para la auditoría financiera, también, se puede encontrar definiciones de evidencia para otro tipo de auditorías, tales como la norma ISSAI 100 denominada Principios fundamentales de auditoría del sector público que aporta un concepto de evidencia más amplio:

La evidencia de auditoría consiste en cualquier información utilizada por el auditor para determinar si la materia/asunto en cuestión cumple con los criterios aplicables. La evidencia puede tomar diversas formas, tales como registros de operaciones en papel y en forma electrónica, comunicaciones por escrito y en forma electrónica con gente externa, observaciones hechas por el auditor y testimonios orales o escritos hechos por la entidad auditada. Los métodos para obtener la evidencia de auditoría pueden incluir la inspección, observación, indagación, confirmación, recálculo, repetición, procedimientos analíticos y/u otras técnicas de investigación. La evidencia debe ser tanto suficiente (en cantidad) para persuadir a una persona conocedora de que los resultados son razonables, como apropiada (en calidad) - es decir, relevante, válida y confiable. La evaluación del auditor sobre la evidencia debe ser objetiva, justa y equilibrada. Los resultados preliminares deben comunicarse y tratarse con la entidad auditada para confirmar su validez (Organización Internacional de Entidades Fiscalizadoras Superiores, 2013, p. 20)

Dicho concepto de auditoría es más amplio sin importar los fines propuestos en el estudio. Continúa esta norma señalando que los auditores deberán evaluar la evidencia de auditoría y obtener de los hallazgos de auditoría y sus conclusiones, tomando en consideración factores cualitativos y cuantitativos y bajo los parámetros que dicten su criterio profesional.

Asimismo, no sólo es relevante tener claro el concepto de evidencia, sino también la manera en que debe gestionarse la documentación de auditoría, dado que la evidencia que recopilemos en el estudio deberá ser adecuadamente resguardada. La ISSAI 200 denominada Principios fundamentales de la auditoría financiera señala la obligación del auditor de resguardar la documentación de auditoría de la siguiente manera.

\section{Documentación}

El auditor debe preparar la documentación de auditoría que sea suficiente para permitirle a un auditor experimentado, sin previo conocimiento de la misma, entender la naturaleza, tiempos y alcance de los procedimientos de auditoría realizados para cumplir con las normas relevantes y los requisitos legales y regulatorios aplicables, los resultados de dichos procedimientos y la evidencia de auditoría 
obtenida, así como los aspectos significativos que surjan durante la misma, las conclusiones a las que se llegue a este respecto y los juicios profesionales relevantes que se hagan para llegar a tales conclusiones. La documentación deberá prepararse en el momento apropiado (Organización Internacional de Entidades Fiscalizadoras Superiores, 2013, Párrafo 70).

Realizar un adecuado respaldo documental constituye una tarea fundamental pues determinará la objetividad y garantía del proceso de recolección y resguardo de la evidencia que respalda los hallazgos de la auditoría.

\section{Normativa técnica que regula la evidencia de auditoría}

La auditoría como toda ciencia posee normas técnicas que regulan los aspectos más importantes de su trabajo, asimismo, la evidencia de auditoría dada su relevancia para el trabajo del auditor se encuentra regulada en diversa normativa técnica de gran relevancia, siendo interés del presente apartado señalar los aspectos más relevantes de dicha reglamentación.

Las más relevantes se presentan en la tabla 1.

\section{TABLA 1}

NORMATIVA TÉCNICA QUE REGULA LA EVIDENCIA DE AUDITORIA

\begin{tabular}{|c|l|}
\hline \multirow{2}{*}{$\begin{array}{c}\text { Normativa técnica } \\
\text { que regula la evidencia } \\
\text { de auditoria }\end{array}$} & $\begin{array}{l}\text { Norma Internacional de la Auditoría } \\
\text { NIA 500: Evidencia de auditoría }\end{array}$ \\
\cline { 2 - 2 } $\begin{array}{c}\text { ISS la auditoría financiera } \\
\text { de Principio fundamentales }\end{array}$ \\
\cline { 2 - 2 } & $\begin{array}{l}\text { ISSAI } 300 \text { Principios Fundamentales } \\
\text { de la Auditoría de Desempeño }\end{array}$ \\
\hline $\begin{array}{l}\text { IISSAI 400: Principios fundamentales } \\
\text { de la auditoría de cumplimiento }\end{array}$ \\
\hline
\end{tabular}

Figura N 1. Normativa técnica que regula la evidencia de auditoría Fuente: elaboración propia. a) Norma Internacional de la Auditoría 500: Evidencia de auditoría

La NIA 500 regula los aspectos vinculados con la evidencia de auditoría de estados financieros, y la responsabilidad del auditor para diseñar y realizar procedimientos de auditoría tendientes a obtener evidencia suficiente y apropiada de los hallazgos de la auditoría.

Dicha norma impone tres características relevantes que debe cumplir la evidencia de auditoría:

- Suficiente: se refiere a la cantidad de la evidencia de auditoría que respalda cada hallazgo, ahora bien, se debe tener cuidado de no caer en la creencia que entre más volumen mejor, pues no se trata de tener mucha evidencia, sino la medida necesaria para respaldar un hallazgo.

- Pertinente: se refiere a la calidad de la evidencia, esta debe poseer altos niveles de calidad que permitan garantizar los resultados del estudio.

- Competente: se refiere a la vinculación que poseen con el hallazgo y la confiabilidad de la evidencia, estar íntimamente vinculados con los hallazgos encontrados y haber sido recopilada de manera adecuada.

La confiabilidad de la evidencia es mayor cuando:

- Se obtiene de fuentes externas a la entidad.

- Existen mejores sistemas de control

- Se obtiene directamente

- La evidencia física es más confiable que la oral

- Documentos originales

b) ISSAI 200: Principio fundamentales de la auditoría financiera

La norma ISSAI 200 establece que la evidencia debe cumplir con dos requisitos:

- Apropiada

- Suficiente 
Textualmente, dicha norma indica: "El auditor debe llevar a cabo los procedimientos de auditoría de manera que pueda obtener evidencia suficientey apropiada para sacar conclusiones sobre las cuales basar su dictamen". (Organización Internacional de Entidades Fiscalizadoras Superiores, 2013, Párrafo 126)

La suficiencia es la medida de la cantidad de evidencia, al igual que en la NIA 500, lo que confirma la importancia de este parámetro; mientras que la característica de apropiada se relaciona con la calidad de la evidencia; es decir su relevancia y confiabilidad. La cantidad de la evidencia requerida depende del riesgo de error de significancia o importancia relativa en la información de la materia en cuestión; a manera de ejemplo, a mayor riesgo mayor será la cantidad de evidencia requerida, por el contrario, entre más apropiada sea la evidencia, es decir, de mayor calidad, menor será la cantidad de evidencia necesaria para sustentar un hallazgo. En consecuencia, las características de suficiencia y apropiada de la evidencia están interrelacionadas; no obstante, el volumen no sustituye el contenido, el simple hecho de obtener más evidencia no compensa su falta de calidad.

Por lo tanto, el auditor deberá considerar tanto la relevancia como la confiabilidad de la información que se va a usar como evidencia. La confiabilidad de la evidencia depende de su fuente y su naturaleza, así como de las circunstancias específicas en las que se obtuvo. La mayor seguridad es proporcionada por una evidencia consistente obtenida de diversas fuentes o de naturaleza diferente en vez de piezas de evidencia consideradas individualmente. Además, al obtener evidencia de diversas fuentes o de naturaleza diferente, es posible identificar elementos individuales que son poco confiables. c) ISSAI 300 Principios Fundamentales de la Auditoría de Desempeño

Igualmente, la norma ISSAI 300 demanda que los auditores obtengan evidencia de auditoría suficiente y apropiada para fundamentar sus hallazgos y formular conclusiones utilizando para ello su juicio profesional y verificando que ella responda a las preguntas de la auditoría. Textualmente, dicha norma dice:

Todos los resultados y las conclusiones de la auditoría deben estar sustentados por evidencia suficiente y apropiada de auditoría. Esto debe estar en contexto, y todos los argumentos pertinentes, las ventajas y desventajas, y perspectivas deben ser consideradas antes de elaborar conclusiones. La naturaleza de la evidencia de auditoría necesaria para llegar a conclusiones en la auditoría de desempeño es determinada por el tema, el objetivo de la auditoría, y las preguntas de auditoría (Organización Internacional de Entidades Fiscalizadoras Superiores, 2009, Párrafo 38).

Señala la importancia de que las conclusiones estén basadas en evidencia cuantitativa obtenida al usar métodos científicos o técnicas de muestreo; así como la combinación y comparación de datos de diferentes fuentes, todo ello con el fin de elaborar un producto de alta calidad y objetividad.

d) ISSAI 400: Principios fundamentales de la auditoría de cumplimiento

Esta norma sigue la misma definición de evidencia utilizada con la ISSAI 300, y adicional la importancia de que el auditor utilice procedimientos de auditoría apropiados de acuerdo con las características del estudio; así mismo su naturaleza y sus fuentes está determinada por los criterios, materia y alcance del trabajo. 
El auditor puede elegir evidencia cuantitativa o cualitativa, o una combinación de ambas, según el alcance de la auditoría. En el caso de la auditoría de cumplimiento incluye una variedad de procedimientos para recopilar evidencia de auditoría y con frecuencia necesitará combinar y comparar la evidencia de diferentes fuentes para satisfacer los requerimientos de suficiencia y pertinencia.

Una vez recopilada la evidencia el auditor debe evaluarla para determinar si la misma es suficiente y pertinente para reducir el riesgo de auditoría a un nivel aceptablemente bajo. El proceso de evaluación requiere tomar en consideración tanto la evidencia que respalde como la que contradiga el producto de la auditoria incluyendo las consideraciones sobre la materialidad. Después de evaluar si la evidencia es suficiente y apropiada dado el nivel de seguridad de la auditoría, el auditor debe considerar la mejor manera formular las conclusiones a la luz de la evidencia.

e) ISSAI 4200 Directrices para las auditorías de cumplimiento asociadas a una auditoría de estados financieros

La norma ISSAI 4200 hace referencia al proceso de evaluación de la evidencia de parte del auditor, señala que al final del estudio, el auditor debe revisar si la evidencia recopilada cumple con las características de suficiencia y pertinencia, y si logran respaldar los hallazgos contenidos en el informe tomando parámetros de materialidad y su criterio profesional.

El proceso de evaluación de la evidencia posee tres fases básicas:

- Obtener la evidencia suficiente y pertinente.

- Evaluar la evidencia e incluir procedimientos adicionales para disminuir el riesgo.

- Finalmente, determinar si es necesario hacer pruebas adicionales y recopilar más evidencia.
Esta norma orienta al auditor en aquellos casos en donde resulta difícil obtener evidencia suficiente y apropiada, en cuyo caso recomienda realizar un análisis de costo-beneficio junto con las consecuencias derivadas de no poder obtenerla.

\section{Técnicas para obtener evidencia de auditoria}

Las técnicas comúnmente utilizadas por los auditores para obtener evidencia, que son:

- Observación: esta técnica consiste en presenciar cómo se desenvuelve un proceso o un procedimiento en curso.

- Inspección: esta técnica consiste en examinar los libros, registros y otros documentos de expedientes o activos materiales. En este procedimiento es fundamental revisar la fiabilidad de los documentos inspeccionados.

- Indagación: esta técnica consiste en requerir información de personas de referencia, pertenecientes o ajenas a la entidad auditada, y comprende desde requerimientos oficiales y por escrito hasta contactos verbales más informales; también puede consistir en entrevistas a personas de referencia, como expertos, para hacerles preguntas. Las entrevistas contarán con la presencia física, o bien con la presencia virtual (por ejemplo, conversaciones telefónicas o videoconferencias), de los interesados. La indagación también puede revestir la forma de cuestionarios o encuestas. Puede utilizarse a lo largo de una auditoría y complementa otros procedimientos. En este punto se debe tener claro que la indagación no representa por sí sola una fuente probatoria suficiente y apropiada, por lo que, para obtener evidencia que reúna estas características, se lleva a cabo en paralelo con otros procedimientos. Las entrevistas resultan más eficaces cuando tienen lugar con personas de referencia 
y con los conocimientos necesarios, es decir, personas con posiciones de autoridad que están legitimadas para hablar o dar su opinión en nombre de la entidad.

- Confirmación: es un tipo de indagación y consiste en conseguir, con independencia de la entidad auditada, una respuesta de terceros en relación con una información concreta.

- Repetición: esta técnica consiste en volver a realizar de modo independiente los mismos procedimientos ya realizados por la entidad auditada, manualmente o por técnicas de auditoría asistidas por ordenador.

- Procedimientos analíticos: engloban la comparación de datos o la investigación de fluctuaciones o relaciones que presentan falta de coherencia.

Una vez que se ha definido la figura de la evidencia de auditoría y su importancia dentro del estudio del auditor, conviene explicar el concepto de prueba en un procedimiento de carácter judicial o administrativo, para posteriormente poder confrontar ambos conceptos y definir sus semejanzas y diferencias, y de gran importancia, tener claro el rol de cada uno.

\section{Prueba en un proceso administrativo o jurisdiccional}

- Concepto de Derecho Probatorio:

Para poder analizar la prueba en el proceso administrativo o jurisdiccional, primero debemos hacer referencia al derecho probatorio, el cual es una rama de las ciencias jurídicas que regula el conjunto de reglas aplicables a la prueba en un proceso de carácter jurídico así como la figura de la prueba en temas procesales: producción, fijación y evaluación; junto con las garantías del debido proceso que deben respetarse a todas las partes involucradas.
- Concepto de prueba:

La prueba es todo elemento que permite encomendar, patentizar, dar fe de alguna situación; es todo aquello que es apto para rememorar un hecho no presente. Ahora bien, también se denomina prueba al medio a través del cual el litigante presenta al juez la verdad del hecho afirmado; así por ejemplo, un documento, el dictamen de un perito, la declaración de un testigo, la confesión, etcétera. Igualmente, se denomina prueba a la actividad o procedimiento desarrollado al ofrecer o producir un medio probatorio.

- Objeto de prueba:

El objeto de prueba es la cosa, la circunstancia o el acontecimiento, cuyo conocimiento es necesario y se debe acreditar en un proceso determinado. Se trata del hecho delictivo y las circunstancias que lo justifican, autores, extensión del daño, entre otros, es precisamente qué se debe probar.

El objeto de prueba posee tres perspectivas importantes que conviene explicar en detalle:

- Órgano de Prueba: es toda persona física encargada de suministrar el conocimiento de los hechos: testigos presenciales; ofendidos; ofensores; peritos, etc. Vinculado con la labor de auditoría, está el auditor que elaboró un estudio en el cual se determinaron causales determinantes de responsabilidad o bien, un tema que sea objeto de debate en vía jurisdiccional quién será llamado para rendir testimonio y declarar sobre los hallazgos y conclusiones de su estudio de auditoría.

- Medio de prueba: es el acto por el cual la persona aporta al proceso el conocimiento de un objeto de prueba: el acto del testimonio, el acto del informe que da o rinde el perito. Se enmarca el medio de prueba justamente como un medio, 
sea este un procedimiento, un acto o un instrumento- por el que la fuente de prueba se integra al proceso. Siguiendo el enfoque de auditoría, el medio de prueba es la declaración en juicio, opiniones, dictámenes o informes de auditoría elaborados como producto de un estudio que se aporta a un proceso legal para ser utilizados como prueba.

- Elemento de prueba: es todo dato objetivo que se incorpora legalmente al proceso capaz de producir un conocimiento cierto o probable, acerca de los extremos de la imputación delictiva. El elemento de prueba es el aporte que brinda el testigo a través de sus manifestaciones en el debate y que deben ser analizadas por el juez u órgano decisor aplicando las reglas de la sana crítica racional. Un ejemplo sería la explicación que da el auditor sobre el desarrollo de la auditoría, la recopilación de la evidencia y la determinación de los hallazgos.

- Tipos de prueba:

El ordenamiento jurídico costarricense prevé la inclusión en un proceso jurisdiccional o administrativo de diferentes tipos de pruebas, que se pueden observar en la figura 1.

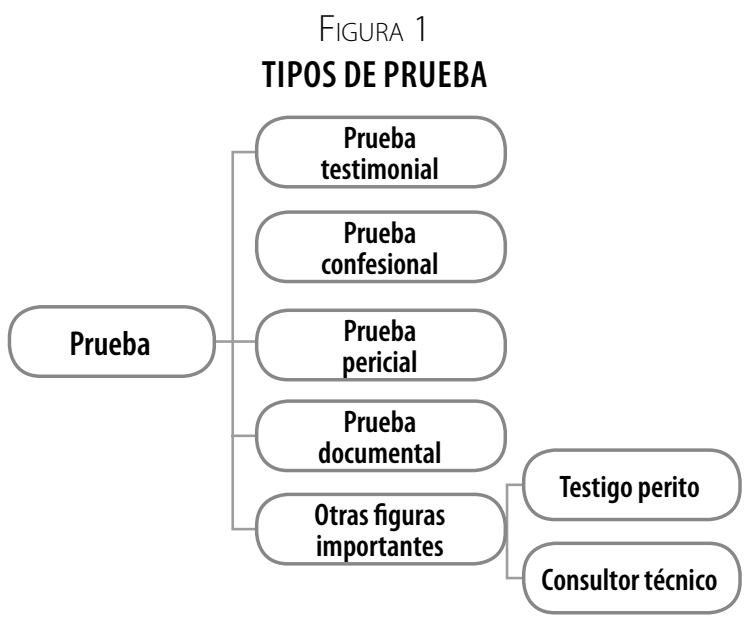

Fuente: Elaboración propia.
- Prueba Testimonial: la prueba testimonial sirve para acreditar hechos que no pueden probarse a través de otros medios de prueba, como la documental; o bien, para ampliar aspectos que no quedaron plasmados en un documento escrito; de tal manera, que el testimonio debe aportar elementos adicionales a los que dice un documento.

El testimonio es la prueba que aporta el testigo al proceso, quien es una persona física que posee conocimiento directo de los hechos. La doctrina lo define (Lunch y Junoy, 2008) como una declaración oral de conocimiento sobre hechos controvertidos prestada, durante el proceso, por un tercero con uso de razón suficiente para declarar. El testigo es el órgano de prueba que aporta el elemento de prueba al proceso.

El Código Procesal Civil de Costa Rica en su artículo 354 establece que el testigo será interrogado sobre los hechos que indica la parte proponente, asimismo, según el numeral siguiente 355 los litigantes podrán repreguntar a los testigos. Por su parte, el artículo 359 de dicho código, señala la oposición a las preguntas y repreguntas que los litigantes podrán hacer a los testigos:

Oposición a preguntas y repreguntas. Si una parte se opusiera a una pregunta o repregunta, el juez hará pasar al testigo a otro departamento para que no se entere del debate. El juez no consignará los debates sobre admisión de preguntas o repreguntas; simplemente hará constar la oposición, de la parte, en la forma más lacónica posible, y la resolución que dicte. Resuelta la oposición, hará pasar de nuevo al testigo. Las protestas se harán en escritos separados. La parte, o el defensor de ésta, que insinuare la respuesta al testigo, será retirado de la audiencia (Asamblea Legislativa, 1989, Artículo 359).

Asimismo, el numeral 355 del Código Procesal Civil establece que el testigo declarará bajo juramente 
y advertido de que si incurre en falso testimonio sería acusado por ello, textualmente dice:

Artículo 358: Práctica de la audiencia.

Los testigos declararán bajo juramento y advertidos de las penas con que la ley castiga el delito de falso testimonio; su declaración versará sobre hechos puros y simples, y estarán obligados a dar razón de su dicho, lo cual deberá exigirles el juez.

A la audiencia sólo podrán comparecer las partes y sus abogados; no obstante, el juez podrá permitir la presencia de otros abogados y de estudiantes de Derecho, para fines didácticos.

Una vez que el juez haya hecho las preguntas al testigo conforme con lo dicho en el artículo 354, las partes o sus abogados podrán hacer sus repreguntas; podrán éstos repreguntar en ausencia de la parte, pero sólo cuando sean apoderados judiciales. Repreguntará primero la parte proponente.

Los testigos declararán seguidamente, procurando que unos no se comuniquen con otros, para lo cual podrán retirarse los que lo hayan hecho.

No será permitido dirigirles preguntas de apreciación, ni consignar opiniones suyas. Podrán leer su declaración o, en su defecto, la leerá el juez o el secretario, y se harán constar estas circunstancias.

De la diligencia se extenderá un acta que firmarán el testigo, las partes, los abogados, los apoderados, el juez y el secretario, acta a la cual le será aplicable lo dicho en el artículo 152 (Asamblea Legislativa, 1989, Artículo 358).

El delito de falso testimonio al cual hace referencia la norma anterior, se encuentra regulado en el numeral 323 del Código Penal, que a la letra dice:
Será reprimido con prisión de uno a cinco años, el testigo, perito, intérprete o traductor que afirmare una falsedad o negare o callare la verdad, en todo o en parte, en su deposición, informe, interpretación o traducción, hecha ante la autoridad competente. Si el falso testimonio fuere cometido en una causa criminal, en perjuicio del inculpado, la pena será de dos a ocho años de prisión. Las penas precedentes se aumentarán en un tercio cuando el falso testimonio sea cometido mediante soborno (Asamblea Legislativa, 1970, Artículo 323).

El Código Procesal Civil enlista las primeras preguntas que se le harán al testigo, que son:

ARTÍCULO 357.-Generales de ley.

A cada testigo se le preguntará:

1. Su nombre, los apellidos, la edad, la profesión u oficio y el domicilio.

2. Si es pariente por consanguinidad o afinidad, y en qué grado, de alguno de los litigantes.

3. Si es dependiente o empleado del que lo presenta, o si tiene con él sociedad o alguna otra relación de intereses o de dependencia.

4. Si tiene interés directo en el proceso o en otro semejante.

5. Si es amigo íntimo o enemigo de alguno de los litigantes, o su compañero de oficina o de trabajo.

El juez interrogará al testigo verbalmente sobre cada una de las preguntas indicadas en los incisos 2) a 5), y sólo consignará la respuesta cuando ésta sea afirmativa; es decir, cuando el testigo manifieste que tiene alguna o algunas de las relaciones con las partes o con el proceso que las referidas preguntas prevén. En caso contrario, bastará con advertir que se hicieron 
al testigo las preguntas dichas y que sus contestaciones fueron negativas (Asamblea Legislativa, 1989, pág. Artículo 358).

Por su parte, el Código Procesal Contencioso Administrativo también posee normativa relevante sobre los testigos, que se aplica tanto en un proceso contencioso administrativo en sede judicial como en un procedimiento administrativo a lo interno de la institución. Dentro de ellos, se destaca el artículo 83 que indica:

1. Las partes o sus representantes, la jueza o el juez tramitador o el Tribunal, según corresponda, podrán requerir la declaración testimonial de la persona funcionaria o de las personas funcionarias que hayan tenido participación, directa o indirecta, en la conducta administrativa objeto del proceso. 2) También, las partes, la jueza, el juez tramitador o el Tribunal podrán requerir la declaración de testigos-peritos, quienes se regirán por las reglas de la prueba testimonial, sin perjuicio de que puedan ser interrogados en aspectos técnicos y de apreciación (Asamblea Legislativa, 2006, Artículo 83).

Continúa este Código indicando la tramitación de la audiencia de la siguiente manera:

ARTÍCULO 106.-

1. Quien presida llamará a los testigos y testigos-peritos; comenzará por los que haya ofrecido el actor y continuará con los propuestos por el demandado.

2. Antes de declarar, los testigos no deberán ver, oír ni ser informados de lo que ocurre en la sala de audiencia.

3. Después de declarar, quien presida podrá ordenar que continúen incomunicados en la antesala, que presencien la audiencia o se retiren.

4. No obstante, el incumplimiento de la incomunicación no impedirá la de- claración del testigo, pero el Tribunal apreciará esta circunstancia al valorar la prueba (Asamblea Legislativa, 2006, Artículo 106).

El numeral siguiente establece el mismo orden para interrogar al testigo contenido en el Código Penal, es decir, primero interroga el proponente y luego la contraparte, y finalmente, los miembros del Tribunal Administrativo podrán realizar preguntas al testigo.

Artículo 107.-

1. Después de juramentar e interrogar al perito, al testigo o al testigo-perito, sobre su identidad personal y las circunstancias generales para valorar su informe o declaración, quien presida le concederá la palabra, para que indique cuánto sabe acerca del hecho sobre el que versa la prueba.

2. Al finalizar el relato, permitirá el interrogatorio directo. Iniciará quien lo propuso y continuarán las otras partes, en el orden que el Tribunal considere conveniente. Luego podrán interrogar los miembros del Tribunal.

3. Quien presida moderará el interrogatorio y evitará que el declarante conteste preguntas capciosas, sugestivas o impertinentes; procurará que el interrogatorio se conduzca sin presiones indebidas y sin ofender la dignidad de las personas. Las partes podrán impugnar las resoluciones de quien presida, cuando limiten el interrogatorio, o podrán objetar las preguntas que se formulen, en cuyo caso el Tribunal podrá ordenar el retiro temporal del declarante. El Tribunal resolverá de inmediato. 
4. Los peritos, testigos y testigos-peritos expresarán la razón de su información y el origen de su conocimiento (Asamblea Legislativa, 2006, Artículo 107).

La citación del testigo está ampliamente regulada en el artículo 361 del Código Penal de la siguiente forma:

\section{Artículo 361.- Citación.}

Si la parte proponente lo considerare, necesario, podrá solicitar verbalmente al juez que cite a los testigos ofrecidos, cuya orden extenderá por escrito. La citación se hará por medio de la parte interesada, quien devolverá al juzgado las órdenes debidamente firmadas por los testigos, a más tardar en el acto de la audiencia. Si la parte lo solicitare, la citación también podrá hacerse por el notificador.

Para que el testigo esté obligado a comparecer, se le deberá solicitar con dos días de antelación, por lo menos, al señalado para su examen. No obstante lo dicho, el testigo podrá presentarse voluntariamente.

Sólo en casos calificados, a criterio del juez, y siempre que el testigo hubiere sido debidamente citado para los dos señalamientos anteriores, se hará un tercer señalamiento, caso en el cual será traído por la fuerza pública; al mismo tiempo se pondrá el hecho en conocimiento de la autoridad penal correspondiente, por medio de una nota, para lo de su cargo (Asamblea Legislativa, 1970, Artículo 361).

En línea similar se encuentra el artículo 77 del Reglamento autónomo de organización y servicio de la jurisdicción contenciosa administrativa y civil de hacienda que aplica en la jurisdicción contenciosa-administrativa cuando señala:

Citación a juicio. Fijada hora y fecha para la celebración del debate oral y público, cada parte debe citar y hacer comparecer sus testigos y peritos, para lo cual quedan a su disposición las cédulas de citación en el Despacho. Solo en los casos en que estos no comparezcan, y se demuestre previamente o durante el debate que el testigo o perito fue debidamente citado, el Tribunal ordenara su presentación por medio de la Fuerza Pública. Si en autos consta medio o lugar para localizar o notificar al perito, el Tribunal realizará la citación respectiva a juicio (Corte Suprema de Justicia, 2008, Artículo 77).

Se debe destacar la posibilidad de traer un testigo mediante la fuerza, pues la normativa establece que el testigo o perito podrá ser llevado a juicio por la Fuerza Pública, elemento de relevancia para el auditor, pues si en algún momento debe declarar en juicio debe ser consiente que existe una obligación legal para cumplir con dicho mandato, al cual no puede oponerse, y que si no llegare puede ser llevado contra su voluntad.

Ahora bien, tanto en sede administrativa como en sede jurisdiccional se respeta la máxima de que nadie puede ser obligado a declarar en su contra, ni en los supuestos contemplados en el artículo 360 del Código Penal que son: cuando por razón de su estado o profesión tengan noticia de hechos que se les hayan comunicado confidencialmente, y cuando sean examinados sobre hechos que importen responsabilidad penal contra el declarante o contra su cónyuge, ascendiente, descendiente o parientes colaterales hasta el tercer grado, inclusive, de consanguinidad o afinidad.

Finalmente, se debe señalar que el testigo tiene derecho a pedir que los medios de comunicación no graben su imagen ni su voz, lo cual resulta relevante, si en algún momento un auditor debe declarar en algún caso importante que sea seguido por los medios de comunicación del país, y no desee ser grabado por ellos, ante esta situación el auditor podrá solicitar la aplicación 
del último párrafo del artículo 331 que regula la participación de los medios de comunicación en la Ley de Protección a víctimas, testigos y demás sujetos intervinientes en el proceso penal, que dice: "Si el imputado, la víctima o alguna persona que deba rendir declaración solicita, expresamente, que las empresas no graben ni su voz ni su imagen, el tribunal hará respetar sus derechos" (Asamblea Legislativa, 2009, Artículo 331).

Prueba confesional: la confesión es la declaración que hace una parte respecto de la verdad de hechos pasados, relativos a su actuación personal, desfavorable para ella y favorable para la otra parte. Para (Casado, 2009) es el reconocimiento que hace una persona del hecho jurídico que se le imputa. La presunción es, sobre todo, un acto jurídico unilateral que requiere la capacidad necesaria para poder disponer del objeto discutido.

Según el artículo 338 del Código Procesal Civil la confesión es plena prueba, es decir, no necesita más prueba que ella para demostrar la veracidad del hecho confesado:

Plena prueba. La confesión judicial prueba plenamente contra quien la hace. Para que haya confesión es necesario que la declaración verse sobre hechos personales contrarios a los intereses del confesante y favorables al adversario. No vale como confesión la admisión de hechos relativos a derechos indisponibles (Asamblea Legislativa, 1989, Artículo 338).

Ahora bien, se debe tener claro que cuando el imputado es una institución pública ésta no podrá confesar en su perjuicio según el numeral 301 de la Ley General de la Administración Pública. Finalmente, el artículo 108 del Código Procesal Contencioso Administrativo regula la recepción de prueba confesional en estos casos judiciales, de la siguiente manera: "Cuando proceda, el Tribunal recibirá la prueba confesional bajo juramento; los jueces, la parte contraria y el propio abogado, podrán hacerle al confesante las preguntas que sean pertinentes, hacer notar las contradicciones y pedir aclaraciones" (Asamblea Legislativa, 2006, Artículo 108).

Prueba pericial: la prueba pericial se refiere al criterio técnico que el cual un experto que emite su opinión sobre un hecho objeto de discusión, generalmente, para casos complejos o técnicos cuya resolución involucra ciencias ajenas al derecho, este punto es importante, pues aquí es donde generalmente entra el auditor como especialista en las ciencias contables y la labor de auditoría, dado que esta profesión incluye aspectos técnicos distintas a las ciencias jurídicas y que son básicas para resolver un hecho controversial; ahora bien, ello aplica para cualquier otra ciencias del conocimiento, como: ingenieros, economistas, psicólogos, planificadores, y demás.

Asociados a la prueba pericial surgen otros conceptos importantes, tales como: perito, quien es la fuente creadora de la prueba pericial, es el órgano de la prueba pericial, el sujeto ajeno al proceso, poseedor de un conocimiento especializado y encargado bien a instancia de parte, bien por designación judicial, de emitir un dictamen pericial; mientras que la pericia es la actividad realizada por un perito de emitir un dictamen pericial, el cual es el informe en donde se plasma la actividad del perito, es decir, es el medio de prueba, mientras que los aspectos técnicos proporcionados al juez gracias a este instrumento es el elemento de prueba.

El artículo 401 del Código Procesal Civil establece cuando será procedente la prueba pericial de la siguiente manera:

Proposición de la prueba. Procederá la prueba pericial cuando haya que apreciar hechos o circunstancias que exijan conocimientos especiales extraños al Derecho. La parte que tenga interés en rendir una prueba pericial expresará, al ofrecerla, con claridad y precisión, los puntos sobre los cuales debe versar el dictamen, y formará, al mismo tiempo, el interrogatorio 
a que deba dar respuesta el perito (Asamblea Legislativa, 1989, Artículo 401).

El Código Procesal Penal señala en su numeral 218 los requerimientos que debe cumplir el dictamen pericial:

El dictamen pericial será fundado y contendrá, de manera clara y precisa, una relación detallada de las operaciones practicadas y de sus resultados, las observaciones de las partes o las de sus consultores técnicos y las conclusiones que se formulen respecto de cada tema estudiado. Los peritos podrán dictaminar por separado cuando exista diversidad de opiniones entre ellos. El dictamen se presentará por escrito, firmado y fechado, sin perjuicio del informe oral en las audiencias (Asamblea Legislativa, 1996, Artículo 218).

Estos informes podrán ser examinados por los testigos o peritos que conozcan de ello, según el 225 del Código Procesal Penal; finalmente, el perito debe guardar reserva de todo lo que llegue a conocer por motivo de la realización de dicho peritaje de acuerdo con el numeral 223 del mismo Código Procesal Penal.

Asimismo, su tramitación en juicio se regula bajo las siguientes reglas del Código Procesal Contencioso Administrativo:

ARTÍCULO 105.-

1. Durante el juicio oral y público se discutirán los informes periciales.

2. Se llamará a los peritos citados, quienes responderán las preguntas que se les formulen. En ese mismo acto, podrán solicitar adiciones o aclaraciones verbales.

3. Los peritos tendrán la facultad de consultar documentos, notas escritas y publicaciones durante su declaración.

4. Si es necesario, quien presida ordenará la lectura de los dictámenes periciales.
5. De ser posible y necesario, el Tribunal podrá ordenar que se realicen las operaciones periciales en la audiencia (Asamblea Legislativa, 2006, Artículo 105).

Estos lineamientos son fundamentales para el auditor quien puede ser llamada a juicio para participar como perito en un proceso judicial o en sede administrativa para dar criterio de aspectos técnicos, no necesariamente de algún informe que hayan realizado, incluso podría ser para pronunciarse sobre el informe de algún otro auditor, o bien, aclarar términos vinculados con su área de especialidad.

Prueba documental: es la prueba por excelente y la que tradicionalmente se utiliza en los procesos administrativos y jurisdiccionales. Es aquella basada en documentos considerados como esenciales para la solución de un conflicto. También se le define como el medio de prueba de naturaleza real, en cuanto constituido por una cosa u objeto, no por una persona ni por una actividad.

Cuando utilizamos prueba documental es necesario corroborar la autoría del documento, verificar firmas, quién lo recibió, y demás aspectos que permitan tener certeza que dicho documento fue elaborado, firmado o conocido por el investigado. Asimismo, este tipo de prueba es el más utilizado, y muchas veces se cae en exceso de documentación que no está vinculada con los hechos controversiales por lo que es necesario tener presente que la prueba documental debe ser suficiente y competente, pero sin caer en sobreabundante, que más bien pueda servir para distraer el objeto en discusión.

El numeral 410 del Código Procesal Penal, señala que junto con la interposición de la demanda se deberá aportar la prueba documental señalada, o en su defecto indicar el lugar en donde se podrá ubicar. El 82 del Código Procesal Contencioso Administrativo establece que la prueba se podrá incorporar al juicio en cualquier tipo de soporte, incluyen el soporte documental. 
Finalmente, la prueba debe ser concreta y atinente a los hechos; asimismo, los medios que se utilizaron para recopilarla deben estar apegados al ordenamiento jurídico.

\section{Otras figuras importantes}

\section{a) Testigo Perito}

La figura del testigo-perito es relativamente reciente, combina los elementos del testigo y del peritaje, para poder comprenderla mejor es necesario precisar en las diferencias de ambas figuras que la originan:

- El testigo se refiere a hechos que ha conocido el testigo por medio de sus testigos, ha visto, escuchado, percibido, y da su versión sobre los hechos

- El perito es un técnico que mediante un dictamen da su opinión y valoración sobre hechos con base en criterios técnicos cuya opinión asesora al juez en temas ajenas al derecho.

El testigo-perito por su parte es una persona que posee conocimientos técnicos especializados, y por lo tanto puede fungir como perito y que a su vez participó de una investigación por lo cual posee conocimiento directo de los hechos, en consecuencia, puede testificar de los hechos que conoció durante la investigación y a su vez, complementarla con una opinión técnica de los mismos.

El Código Procesal Penal en su artículo 214 establece la obligación de que el perito posea título habilitante que lo acredite como experto en la materia, asimismo, el artículo 83 inciso 2) del Código Procesal Contencioso Administrativo señala la posibilidad de que el Tribunal de juicio interrogue al testigo perito, tanto de los hechos como de la materia técnica que lo acredita como experto, cuando dice: "2)También, las partes, la jueza, el juez tramitador o el Tribunal podrán requerir la declaración de testigos-peritos, quienes se regirán por las reglas de la prueba testimonial, sin perjuicio de que puedan ser interrogados en aspectos técnicos y de apreciación" (Asamblea Legislativa, 2006, Artículo 214).

Lo anterior es relevante porque establece que el testigo-perito deberá declarar de los hechos que conoce como testigo pero también podrá ser consultado por cualquier elemento técnico, dado que funge como perito. Para el caso de los auditores, se podría fungir bajo esta figura cuando realizamos un estudio de auditoría y debemos declarar de cómo fue el proceso de auditoría, cómo se determinó el campo de estudio, quién nos suministró la información, donde la ubicamos, que tipo de pruebas se realizaron, y demás hechos que no se plasman en un informe de auditoría, no obstante, también puede ser consultado por elementos técnicos, normas de auditoría, procedimientos contables, estén o no incluidos en el informe, pues como perito cumple el papel de asesor técnico del juez.

De tal manera, que si producto de un estudio de auditoría somos llamados a participar en un juicio en calidad de testigos peritos debemos tener claros ese doble rol, en donde no sólo se nos puede interrogar sobre los hechos que conocimos directamente por nuestros sentidos, sino también, sobre la técnica de nuestra especialidad.

b) Consultor técnico

Esta figura no es propiamente un medio de prueba, pero resulta relevante incluirla en el presente análisis, pues puede ser otro papel que podría desempeñar un auditor en un proceso judicial o administrativo.

El consultor técnico es un especialista en un área técnica que asesora a las partes, sea al abogado acusador o al abogado defensor con el fin de que éste pueda plantear preguntar, objeciones y alegatos a un perito o testigo perito en ámbitos técnicos de la declaración. 
El artículo 103 del Código Procesal Contencioso Administrativo, lo regula de la siguiente forma:

ARTÍCULO 103.-

1. Cualquiera de las partes podrá solicitarle al Tribunal la asistencia de un consultor en una ciencia, arte o técnica, el cual decidirá sobre su designación, según las reglas aplicables a los peritos, sin que por ello asuman tal carácter. El Tribunal podrá citar a la audiencia a un consultor, para efectos de ilustración y, excepcionalmente, podrá autorizarlo para que interrogue a los peritos y testigos.

2. El consultor técnico podrá presenciar las operaciones periciales y acotar observaciones durante su transcurso, sin emitir dictamen; además, de sus observaciones se dejará constancia.

3. También, durante la audiencia las partes podrán tener a un consultor para que las auxilie, en los actos propios de su función (Asamblea Legislativa, 2006, Artículo 103).

Por su parte, el Código Procesal Penal en su artículo 126 permite la participación de consultores técnicos como asesores de las partes, es decir, no son asesores del juez sino del Ministerio Público o de los acusados.

ARTICULO 126.-

Consultores técnicos: Si, por las particularidades del caso, el Ministerio Público o alguno de los intervinientes consideran necesaria la asistencia de un consultor en una ciencia, arte o técnica, lo propondrán al Ministerio Público o al tribunal, el cual decidirá sobre su designación, según las reglas aplicables a los peritos, sin que por ello asuman tal carácter. El consultor técnico podrá presenciar las operaciones periciales, acotar observaciones durante su transcurso, sin emitir dictamen, y se dejará constancia de sus observaciones.

Podrán acompañar, en las audiencias, a la parte con quien colaboran, auxiliarla en los actos propios de su función o interrogar, directamente, a peritos, traductores o intérpretes, siempre bajo la dirección de la parte a la que asisten (Asamblea Legislativa, 1996).

Igualmente, el Reglamento autónomo de organización y servicios de la jurisdicción contencioso administrativa y civil de hacienda contempla la posibilidad de que alguna de las partes contrate o solicite un consultor técnico.

El auditor podría ser llamado a un proceso para servir de consultor técnico a los abogados de las partes, cuando se traten temas de su ámbito de competencia, en cuyo caso debe estar atento y explicarle al abogado los temas técnicos en lenguaje sencillo para que éste pueda plantear las preguntas y alegatos más convenientes según el tema en discusión.

\section{Similitudes y diferencia entre evidencia de auditoría y prueba en un procedimiento judicial o administrativo}

El nuevo rol que desempeña el auditor en la sociedad es activo y amplio, ello exige que dicho profesional esté preparado para todo; es decir, no sólo debe limitarse a realizar estudios de auditoria que estén dentro de su competencia, sino también, estar en capacidad de preparar prueba, dado que dentro de los productos que pueden surgir de su trabajo se incluyen las investigaciones preliminares y las denuncias penales, la cuales poseen un carácter distinto a los informes de auditoría o dictámenes de estados financieros.

De esta realidad es que surge la necesidad de establecer las diferencias entre evidencia de auditoría y prueba en términos jurídicos. La evi- 
dencia de auditoría es aquella que recopilamos durante el estudio de auditoría con el fin de fundamentar los hallazgos, ésta debe ser suficiente, competente y pertinente, o suficiente y adecuada, para ello podemos recurrir a distintas técnicas de recopilación de evidencia como: observación, inspección, indagación, repetición, confirmación y procedimientos analíticos.

Por su parte, prueba es todo elemento que permite comprobar un hecho controversial, y en sus diferentes tipos: testimonial, confesional, pericial o documental, le permiten al juez tomar una decisión definitiva de un caso.

Ahora bien, el auditor durante su estudio recopila evidencia de auditoría que al incorporarse en un procedimiento administrativo o jurisdiccional se convierten en prueba; no obstante, no toda la evidencia de auditoría puede ser considerada como prueba, por ejemplo: la inspección o la indagación, si bien son técnicas adecuadas para recopilar evidencia, no pueden ser admisibles para recopilar prueba, por la formalidad que ésta última requiere y según las normas aplicables en la legislación.

El auditor debe estar consciente de que si bien, la evidencia de auditoría posee gran similitud con la prueba, no toda la evidencia puede ser considerada como prueba; de tal manera, que cuando deba elaborar un producto que posee efectos jurídicos debe ser más cuidadoso y diligente con la recopilación de la misma, temas como: autenticidad de documentos, confirmación de su autoría, individualización de actuaciones, precisión de conceptos técnicos, selección de criterios y similares revisten de mayor relevancia en este tipo de productos, que en la auditoría tradicional.

La composición del hallazgo: condición, criterio, causa y efecto reviste un carácter distinto cuando nos referimos a hechos con consecuencias jurídicas, la condición debe ser objetiva, demostrada en evidencia competente, el criterio debe ser necesariamente un elemento de carácter normativo que ha sido vulnerado, la causa son los motivos que llevaron al incumplimiento del ordenamiento jurídico, y el efecto, es la violación en sí misma, que merece una revisión en sede administrativa o jurisdiccional.

Ahora bien, también existe la posibilidad de que un informe de auditoría sea impugnado en sede jurisdiccional, en este caso se debe tener presente que si bien, la recopilación de evidencia se hizo para sustentar los hallazgos de un informe, en el momento en que éste se discute en sede jurisdiccional la evidencia se convierte en prueba, por lo tanto, del bagaje de evidencias recopiladas se debe procurar aquella que cumpla de mejor manera los requisitos de la prueba en sede jurisdiccional, dicha selección y determinación de la estrategia a seguir para defender el informe debe hacerse siempre con la asesoría del abogado.

Finalmente, si bien el auditor es y siempre será auditor - no debe ser abogado- la función moderna de la auditoría le exige tener conocimiento de las regulaciones propias de la prueba, pues cada vez es más frecuente que el auditor participe con su investigación de un proceso de carácter jurídico, lo cual cambia la naturaleza de la evidencia, pues esta deja de tener efectos únicamente para sustentar hallazgos de un informe y se convierten en la prueba que demuestra un hecho controversial.

\section{CONCLUSIÓN}

El presente documento pretende destacar la necesidad de que el auditor considere las particularidades propias de la evidencia de auditoría y la prueba en un proceso judicial o administrativo; ello pues aun cuando estas figuras están íntimamente vinculadas y poseen una gran relación, no son sinónimos.

La evidencia de auditoría pretende respaldar los hallazgos, conclusiones y recomendaciones del auditor, y se recopilan por distintas técnicas, reguladas en normativa técnica; por otra par- 
te, la prueba; si bien, se puede recopilar en un proceso de auditoría, debe respetar el marco de legalidad vigente, y su obtención demanda un proceso de recopilación más meticuloso dado que será objeto de una revisión minuciosa en un proceso judicial o administrativo, en el cual se le aplicarán las normas del debido proceso.

Esta diferencia resulta esencial, pues la labor del auditor está sufriendo cambios importantes, tradicionalmente el auditor era el responsable de emitir una opinión sobre los estados financieros de una entidad o institución, y en raras ocasiones acudía frente a un juez por causa de su trabajo; en la actualidad, existen múltiples figuras y supuestos por los cuales un auditor puede ser llamado a un proceso judicial o administrativo, y en que la evidencia de auditoría puede convertirse en prueba.

Como resultado de ello el auditor debe considerar las regulaciones propias de la prueba cuando realiza su labor de fiscalización; máxime cuando investiga un caso que eventualmente podría ser considerado como una violación al ordenamiento jurídico, dado que en éstos supuestos la rigurosidad para la recopilación de la prueba reviste de una trascendencia mayor.

Si bien, se debe tener presente que el auditor no es abogado, cada vez es más relevante que conozca de estos conceptos jurídicos para que pueda realizar adecuadamente su trabajo y sostener los resultados de su investigación; de tal manera, que las conclusiones y recomendaciones que emita no sean objetadas por deficiencias probatorias.

Concluyo este documento instando al auditor a prepararse para los nuevos retos que enfrenta la profesión, y que implican no solo un incremento en los productos de auditoría, sino en los roles que puede desempeñar este profesional, lo cual incluye un papel en los procesos judiciales o administrativos, y por lo tanto, debe estar preparado para cumplir con ella adecuadamente.

\section{REFERENCIAS}

Armas García, R. (2008). Auditoría de gestión: conceptos y métodos. Cuba: Editorial Félix Varela.

Asamblea Legislativa . (1970). Código Penal. San José, Costa Rica: SINALEVI.

Asamblea Legislativa. (1989). Código Procesal Civil. San José, Costa Rica: SINALEVI.

Asamblea Legislativa. (1996). Código Procesal Penal. San José, Costa Rica: SINALEVI.

Asamblea Legislativa. (2006). Código Procesal Contencioso Administrativo. San José, Costa Rica: SINALEVI.

Asamblea Legislativa. (2009). Ley n. 8720 denominada Ley de Protección a víctimas, testigos y demás sujetos intervinientes en el proceso penal. San José, Costa Ricaq: SINALEVI.

Casado, M. L. (2009). Diccionario de Derecho. Argentina: Valleta Ediciones.

Corte Suprema de Justicia. (2008). Reglamento autónomo de organización y servicio de la jurisdicción contencioso administrativa y civil de hacienda. San José, Costa Rica: SINALEVI.

Ginés Castellet, N. (2011). La prueba documental. España: J.M. Bosch Editor.

International Federation of Accountants. (2009). Norma Internacional de Auditoría NIA 500: Evidencia de auditoría. México: Instituto Mexicano de Contadores Públicos.

Lunch, X., \& Junoy, J. (2008). El interrogatorio de testigos. España: J.M. Bosch Editor.

Mantilla, S.A., \& Cante, S. Y. (2005). Auditoría del Control Interno. Bogota, Colombia: Ecoe Ediciones Ltda.

Midón, M. (2007). Derecho probatorio: parte general, Volumen 1. Argentina: Ediciones Jurídicas.

Organización Internacional de Entidades Fiscalizadoras Superiores. (2009). ISSAI 100 - Principios fundamentales de auditoría del sector público. Austria: INTOSAI.

Organización Internacional de Entidades Fiscalizadoras Superiores. (2009). ISSAI 300 Principios Fundamentales de la Auditoría de Desempeño. Austria: INTOSAI.

Organización Internacional de Entidades Fiscalizadoras Superiores. (2013). ISSAI 200 denominada Principios fundamentales de la auditoría financiera. Austria: INTOSAI.

Recibido: 07 de julio de 2014 Aceptado: 20 de agosto de 2014 